Several natural components abundant in the fluid phase of human breast-milk have been shown to be inhibitors of complement activation in vitro, particularly the classical pathway. These include lysozyme, lactoferrin, lactalbumin alpha and other ligand chelators, complement regulator proteins and other specific soluble inhibitors of complement activation. Their physiological significance probably resides in their ability to restrict in vivo complement activation to specialized (compartmentalized) sites on the cellular membrane structures in human milk, represented by the abundant surface area of the milk fat globule membranes. This would serve to prevent inflammatory-induced tissue damage of the delicate immature gastrointestinal tract of the newborn as well as the mammary gland itself. A number of recognized and potential inhibitors of complement activity in human milk and other biological fluids are hereby reviewed, with a proposal of their physiological significance.

Abbreviations: HBM, human breast-milk; APC, alternative complement activation pathway; MAC, membrane attack complex (C5b-9); MFGM, milk fat globule membrane

Key words: Human breast-milk, complement system, inhibitors, milk fat globule membrane

\section{Inhibitors of complement activity in human breast-milk: a proposed hypothesis of their physiological significance}

\section{Michael Oladipo Ogundele}

Department of Immunology, Georg-August University, Kreuzbergring 57, D-37075 Göttingen, Germany

Tel: (+49) 551395812

Fax: (+49) $55139-5843$

Present address: Department of Medical Informatics, University of Applied Sciences, Luxemberger Str. 10, D-13353 Berlin, Germany

Proofs and reprint requests to: Dr M. O. Ogundele, Foehrer Str. 6, D-13353 Berlin, Germany.

Tel/Fax: (+49) 3045490489

E-mail: mogundel@yahoo.com

Internet: http://www.tfh-berlin.de/ s670036

\section{Introduction}

The serum complement (C) system consist of at least 19 proteins, mostly in pre-activated enzymatic forms, activated in a multi-step cascade reaction via either the classical or alternative pathways (Figure 1). The classical pathway is activated mainly by antigenantibody complexes (IgG or IgM mostly) starting with C1q. ${ }^{1}$ The alternative pathway (APC) utilizes active sites (such as are present on zymosan, yeast, cobra venom, Gram-negative bacteria, sheep erythrocytes and human cells deficient in the expression of regulatory molecules) in the presence of properdin, serum factors $B$ and $D$, to activate $C 3$. The two pathways proceed uniformly after $\mathrm{C} 3$ activation to the formation of (C5b-9) membrane attack complexes (MAC), capable of inserting into biological membranes and producing cell lysis and death. ${ }^{2}$

The immunochemical levels of certain complement components in the human colostrum (C3, C4) have been found to approach that of normal serum levels. ${ }^{3-5}$ However, only a small fraction of the serum complement activity is measurable using in vitro assays. A number of factors might be accountable for this effect. Firstly, there is apparently a relative deficiency of some of the essential components of the complement cascade system. For example, properdin, a stabilizer of fluid-phase alternative pathway convertases, has been reported to be either absent in human breast-milk (HBM), or only present in minute quantities less than $1 \mu \mathrm{g} / \mathrm{ml}^{6}{ }^{6}$ It is also possible that some of the identifiable complement components, though native, might be haemolytically and physiologically inactive. ${ }^{7}$ Thirdly, there is a wide array of natural human breast-milk components which have been shown to inhibit complement activity in vitro.

It has been observed that cow's milk contains some inhibitory effect on the activity of serum complement. This inhibitory effect in bovine milk has been partly ascribed to a prozone phenomenon of excessive antibodies in undiluted milk, and other unexplained factors in heated milk, particularly in casein micelles. ${ }^{8,9}$ A similar inhibitory effect of breast-milk on the serum complement activity has also been 


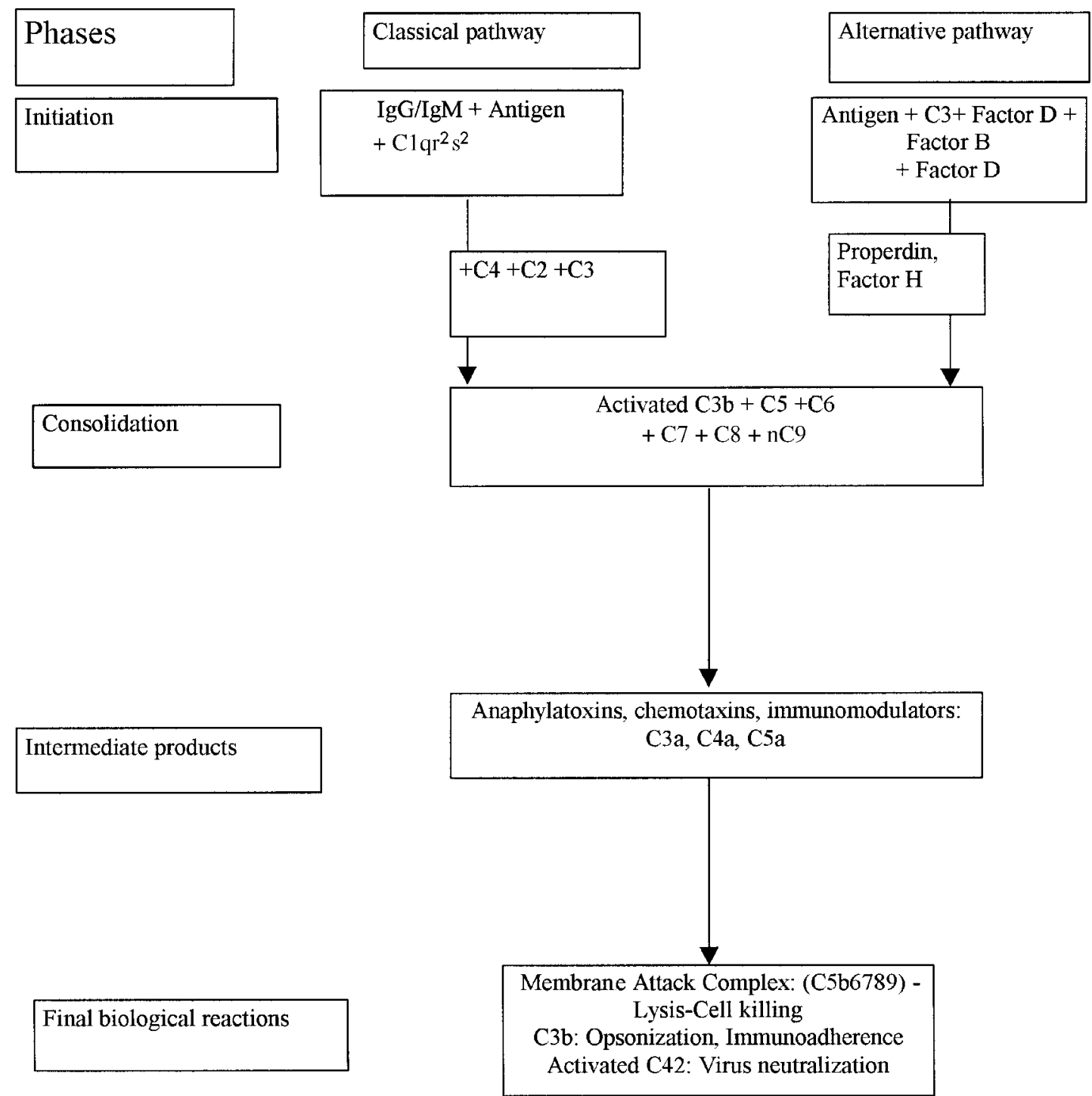

FIG. 1. Diagrammatic representation of the classical and alternative pathways of complement activation.

observed in human milk, although the inhibitory effect appears to reside mainly in its fat component. ${ }^{10}$ This inhibitory activity presents unequivocal evidence for the presence of anti-complement factors in human milk (Table 1).

\section{Soluble Inhibitors of Complement Activation in Human Breast-Milk}

$\alpha$-Lactalbumin and ligand ion chelators

Some milk proteins, such as $\alpha$-lactalbumin, and lowmolecular weight ligands, such as citrates and phosphates, are known to have high affinity binding sites for calcium. ${ }^{11}$ They may therefore act as inhibitors of complement indirectly by chelating the divalent ions required for complement activation. ${ }^{12}$

\section{Lactoferrin}

Lactoferrin is a glycoprotein with an approximate MW of $80 \mathrm{kDa}$. It is produced by epithelial cells, neutrophils and monocyte macrophages. It is present as a major antimicrobial component of many body fluids, including tears, saliva, seminal fluid and pancreatic secretions. The highest concentration of lactoferrin (up to $6 \mathrm{mg} / \mathrm{ml}$ ) is found in the colostrum and this gradually falls, as lactation proceeds, to a constant value in mature milk (approx. $1 \mathrm{mg} / \mathrm{ml}$ ) after about 4 months of lactation. It is resistant to acid denaturation during its passage through the intestinal tract. $^{3,4}$

Lactoferrin in tears from humans and several animals has been shown to inhibit the classical pathway of complement activation, by preventing the formation of $\mathrm{C} 3 / \mathrm{C} 5$ convertase. It competitively 
Table 1 List of proven and possible inhibitors of complement activity in human breast-milk

\section{Lactoferrin}

Fat globule membrane

Free lipids in solution

Soluble protectin (CD59)

Poly $\lg \mathrm{A}$ and antigen-bound $\lg \mathrm{A}$

Proteases

Bacteria and other pathogenic contaminants

Citrates, phosphates and proteins

Lysozyme

$\alpha$-Lactalbumin

Soluble IgG-, IgM-antigen complexes

Other unidentified factors
Inhibits the assembly of the classical C3/C5 convertase

13,14

Non-specific target surface for active $C$ fragments

10

Chelation of calcium and magnesium, non-specific binding of lipophilic $C$ fragments

Inhibits MAC formation

Inhibits IgG-mediated complement activation

18,19

Non-immune complement consumption

Consumption of classical or alternative path $\mathrm{C}$ components

$18,27,28$

Binding of ionic calcium required for optimal $\mathrm{C}$ activity

Binding of ionic calcium required for optimal $\mathrm{C}$ activity, Hydrolysis of native $\mathrm{C}$ components

Binding of ionic calcium required for optimal $\mathrm{C}$ activity

Fluid-phase complement consumption

Non-specific $\mathrm{C}$ consumption inhibits the binding of C2 to EA14 cells. This inhibitory effect is dose-dependently reversed by the addition of $\mathrm{Fe}^{3+}$ ions. ${ }^{13,14}$

\section{Lysozyme}

Lysozyme is an acid- and heat-stable enzyme that is abundant in the breast-milk and in most other mucosal body fluids. The concentration of lysozyme in the colostrum is approximately $40-100 \mu \mathrm{g} / \mathrm{ml}$ and gradually increases as the lactation progresses. ${ }^{3,4}$

Lysozyme catalyzes the hydrolysis of the $\beta(-1,4-)$ linkage between $N$-acetylglucosamine and $N$-acetylmuramic acid in the bacterial cell wall. The enzyme lyses mostly Gram-positive and a few Gram-negative bacteria, or induces their aggregation. Lysozyme interacts with other immunoprotective components of human milk in exerting its antimicrobial actions. It is bacteriocidal for $E$. coli and Salmonella spp. in the presence of sIgA and C3 complement component.

Lysozyme has been found to inhibit the classical pathway of serum complement activity in a dosedependent fashion, especially within the range of pathological concentrations. The inhibitory effect of lysozyme seems to be minimal under physiological conditions in the absence of inflammation, since only a minimal inhibition was produced within this physiological range. The inhibitory effect of lysozyme might be related to its ability to degrade certain glycoprotein components of native complement factors. ${ }^{15}$

\section{Native and aggregated immunoglobulins}

IgA is the most abundant immunoglobulin in the colostrum and breast-milk, and constitutes the major protein content in the colostrum. ${ }^{3,4}$ It has been long argued that IgA activates neither the classical nor the alternative complement pathway. Subsequent experiments, however, have shown that it is capable of limited activation of the complement system. IgA myeloma has been shown to activate the classical pathway. ${ }^{16}$ Aggregated IgA and IgA coated onto plastic (possibly denatured), but not antigen-bound IgA have also been shown to activate the alternative pathway of complement (APC). ${ }^{17}$ Fab fragments of IgA have also been previously discovered to be capable of activating the APC. ${ }^{20}$

In a solid-phase antigen-dependent C3b-binding ELISA system, IgA antibodies were unable to activate complement by either pathway. IgA antibodies were found to inhibit significantly the activation of complement initiated by antigen-bound polyclonal or mixed monoclonal IgG antibodies. This inhibition was found to be independent of the ability of the IgA antibodies to compete against the IgG antibodies in binding to either antigen or C1q. ${ }^{18,19}$

IgA Fab fractions have also been found to inhibit the activation of complement system. The invasive pathogenicity of certain mucosal bacteria has been postulated to be related to their possession of IgA1 proteases, which cleave secretory IgA1 antibodies to antigen-binding Fab-a fragments. These fragments are not only defective in mucosal defence properties, but also protect the organisms from other immune effector systems, such as the classical pathway of complement activation. ${ }^{18}$

\section{Soluble forms of membrane complement regulatory proteins}

Protectin (CD59), a cell surface complement regulatory protein, that binds and inactivates the 
membrane attack complex (MAC), has recently been discovered to be secreted and embedded in milk fat globules. ${ }^{21}$ It is also present in soluble forms in human milk. ${ }^{22}$ The soluble forms could have been shed from the milk fat membrane, and possibly could also partly arise from aging neutrophils in breastmilk. ${ }^{23}$ The extent of the inhibitory effect of this protein under physiological conditions, however, remains unknown. Decay-accelerating factor (DAF) has been detected on most epithelial cells at sites of mucosal immunity, and its soluble form has been found in various body fluids. ${ }^{24}$ This complement regulatory molecule has, however, not yet been specifically reported in breast-milk or on mammary gland epithelial cells. Vitronectin, which has also been detected in human tears, is yet to be described in human breast-milk. ${ }^{25}$

\section{Other specific complement cascade inhibitors}

Factor $\mathrm{H}$ has been measured immunochemically in the human milk, ${ }^{26}$ its serum level being approximately $0.233 \mu \mathrm{g} / \mathrm{ml}(0.12 \%)$. It is a specific inhibitor of the APC, and its relatively low level in human milk might raise doubts as to its physiological significance on mucosal complement activity. In our laboratory, C1-INH could not be detected in human milk, using a single radial immunodiffusion method with a detection limiting value of $0.048 \mathrm{~g} / \mathrm{l}$. Factor I (C3 inactivator) has also not been reported previously in human breast-milk.

\section{Milk proteases as possible inhibitors of complement activation}

Heat-stable milk proteases, including plasmin, are present in breast-milk. They have been shown to be capable of splitting $\beta$-casein in milk, ${ }^{27,28}$ and could contribute to the complement-inhibitory activity of human milk by non-immune splitting of native complement components.

\section{Other potential inhibitors}

There is no conclusive evidence to suggest that all the possible inhibitors of complement system in milk have been identified. Further research might yet discover many other unidentified natural components or contaminants, which directly or indirectly contribute to the observed diminution of inflammatory reactions on the mucosal surfaces, in the presence of active potentially inflammatory protective mechanisms. This would be in line with the mucosal antiinflammatory hypothesis proposed by Goldman and co-workers. ${ }^{29}$ However, their suggestion of insignificant functionality of complement, based on the assumption of minimal levels in human milk, would not be supported by the discovery of levels of certain complement components approaching those available in serum. The presence of such a wide array of inhibitors, apparently serve teleologically to minimize the undesirable inflammatory processes, while permitting the infant to benefit from the other noninflammatory activities of the complement.

Bacterial and other pathogenic contaminants of human milk might indirectly constitute a source of complement depletion, by wasting the potentially useful native components, and diminishing the levels effectively delivered to the nursing infant. This is particularly so, based on the observation that human milk is rarely sterile, often moderately contaminated with non-pathogenic normal skin flora. ${ }^{30}$ It also sometimes contains potential pathogens, which however seem to produce no ill effects on the suckling infant. ${ }^{31}$

Similarly, soluble IgG or IgM complexes, with or without antigens, secreted into the milk from the mother's blood circulation, could potentially activate and deplete the mucosal complement.

\section{Milk Fat Globule Membrane as an Inhibitor of Breast-Milk Complement}

Human milk consists mainly of a protein, sugar and cellular suspension in 95\% water and $2-5 \%$ lipid fraction. The cellular elements consist of macrophages, neutrophils, lymphocytes and mammary gland epithelial cells. The lipid fraction consists mainly of triglycerides enveloped in a complete trilaminar unit of biological cell membranes, the milk fat globule membrane (MFGM). This membrane is derived from the apical region of the mammary gland epithelial cells, and is budded off around the milk lipids as they are being secreted by the cells. ${ }^{32}$ The MFGM is similar to any other cell membrane of eukaryotic cells ${ }^{33}$

The inhibitory effect of human milk has been found to be progressively diminished with increasing speed of centrifugation and the degree of de-fattening. ${ }^{10}$ Two possible explanations have been proposed for these observations. The MFGM might be either activating the complement reaction cascade, and thereby depleting serum complement components, or acting as an alternative reaction site, preventing the assembly of the active complement components on the target sheep red blood cells (SRBC).

Free fatty acids (FFA) in milk are also capable of forming soaps with calcium and magnesium ions, thereby preventing optimal activation of the complement system reaction cascade. ${ }^{12,34}$ They could also bind to the more lipophilic components of the complement system, preventing them from participating in activation reactions by making them chemically inactive. 


\section{Physiological Significance of Complement Activities and their Soluble Inhibitors in Human Breast-Milk}

Despite the levels of some components comparable to those in serum, activation of human milk complement in the fluid phase has been found to be less than optimal under physiological conditions, requiring additional divalent cations. However, in vitro activities of human milk complement have recently been demonstrated, including haemolysis of sensitized SRBC and bacteriolysis of a serum-sensitive $E$. coli, $S$. aureus and $S$. epidermidis. Furthermore, nonimmune mechanisms of complement activation have been demonstrated in the mucosal secretions of the lachrymal gland, ${ }^{35}$ suggesting that the inhibition of classical pathways of complement activation at these mucosal sites could still be circumvented, to enable some of the physiological roles of the complement to be realized.

Apart from the complement and free fatty acids (FFA), most of the available antimicrobial agents in human milk are bacteriostatic. Since bactericidal FFA are also present in the artificial formula feeds, and they do not seem to contribute to the protection of formula-fed infants, ${ }^{36}$ the complement system should be regarded as potentially the source of a significant contribution to the increased resistance of breast-fed infants against infection; ${ }^{37}$ Furthermore, clinical studies have shown that a deficient secretion of complement components in human milk constitutes a higher risk factor for the development of mastitis in the lactating mother. ${ }^{38}$ Breast-fed infants are also known to possess higher levels of complement components and activities compared to their formula-fed counterparts. ${ }^{44}$ Human milk, therefore, constitutes an important source of either native components, absorbed from the infantile intestines, or some other humoral factors capable of enhancing the synthesis and activities of the complement system in vivo.

The levels of both mucosal lysozyme and most other soluble inhibitors tend to increase during periods of infection in parallel with the complement components. ${ }^{38}$ Their inhibitory effects under physiological conditions might, therefore, be expected to be minimal, and sharply increase with the onset of fullblown infections. The protective functions of the various body defence factors at the mucosal surfaces, including those in the human milk, have been proposed to be carried out mainly with the exclusion of inflammatory processes. ${ }^{29}$ Increased overall physiological activities of these mucosal factors would be an indication for a greater need for the suppression of inflammatory components of their activities, hence the need for increased inhibitory activities.

The observation of specific physiological functions attributable to the complement system, as listed above, in the presence of soluble inhibitors, would suggest that the mucosal complement might be actively involved in such activities as bacteriolysis, opsonization and immuno-adherence, neutralization of certain viruses, as well as modulation of immune responses at mucosal surfaces (see Figure 1), in the absence of, or with the suppression of inflammatory processes. $^{39}$ This would serve to protect the body against the constant threat of foreign invaders. The presence of secretory anti-complementary components would then serve to protect the tissues against secondary damage during acute overwhelming infections, where excessive inflammatory reactions of the complement might be undesirable.

\section{An Hypothetical Viewpoint of the Physiological Mechanisms of Human Breast-Milk Complement Activation and the Role of Milk Fat Globule Membrane}

The presence of such a wide variety of potent soluble inhibitors of complement activity in human breastmilk, particularly those of the classical pathway, would prevent their optimal physiological activities in the fluid phase. However, clinical and experimental evidence suggest that the complement system is physiologically active in vivo. ${ }^{38,44}$ The activation of the complement might, therefore, be expected preferentially to take place outside the fluid phase, on the surface of any widely available solid phase, such as milk fat globule membranes, with the alternative pathway being favoured over the classical pathway.

In vivo, MFGM appears to be the most suitable template for complement activation, where all the products of complement activation could be segregated together to obtain a relatively high local concentration and maximal effect on the membranebound antigens. A number of observations and assumptions point to the possible role of the MFGM as the major site of complement activation in vivo.

Firstly, the MFGM possesses independent mechanisms for the sequestration and trapping of certain pathogenic bacterial antigens by attachment to its surface glycoproteins. ${ }^{40}$ Secondly, our recent studies have provided evidence that many native and activated products of complement are closely bound to the MFGM. For example, in a modified $\mathrm{CH} 50$ assay, where non-specific haemolytic effects of FFA have been inhibited, up to $50 \%$ of complement activity is lost by de-fattening of whole-milk through centrifugation. The unidentified components of cow's milk capable of preferentially binding to $\mathrm{C} 1 \mathrm{q}$ might be represented in human milk by the MFGM. ${ }^{41}$ Thirdly, protectin (CD59), a membrane surface complement regulatory molecule, has been found to be expressed on the MFGM. ${ }^{21}$ Homologous cells are protected from the lytic effect of complement through the expression of surface membrane regulatory molecules, such as decay-accelerating factors (DAF, CD 55), membrane 
cofactor protein (MCP), homologous inhibitor of reactive lysis (protectin, CD 59), C3 receptors 1,3 and 4 (CD35, CD11b, c/18). This would suggest a physiological mechanism by which the MFGM is protected in vivo, at least by protectin, in the presence of ongoing antigen-induced complement activation, without leading to a secondary damage of the MFGM. Lastly, most milk-borne macrophages are found to be laden with fat vacuoles which they have ingested in vivo. ${ }^{42,43}$ The explanation for this observation would seem to be based on the deposition of $\mathrm{C} 3$ fragments or IgG on the MFGM, which opsonizes them for phagocytosis by macrophages.

The abundant supply of MFGM in human milk and its ability to bind to both native and activated complement components, as well as particulate antigens, which are also able to independently activate the alternative pathway, even in the absence of specific antibodies, makes MFGM the most likely site for physiological activation of human milk complement. While pathogens to which the mother is already sensitized might be disposed of by the large amounts of secretory IgA (sIgA) in breast-milk, newly acquired antigens from the environment, which might not be able to immediately stimulate the production of specific antibodies at the mucosal site, could be attacked by the breast-milk complement through the aid of the MFGM, thereby protecting both the mammary gland and the suckling infant against infection.

The MFGM might assume particular significance when the level of particulate antigens, such as bacteria, overwhelm the inhibitory ability of the sIgA and the other bacteriostatic components of human milk fluid-phase. They are then available to be bound on the surface of the MFGM where they could activate the complement system and subsequently be killed by lysis, without significant interference of the wide variety of inhibitors present in the fluid phase.

The ability of the MFGM to bind C3 opsonin fragments, thereby enhancing its phagocytosis and ultimate degradation by macrophages, might account for at least one of the mechanisms by which it is ultimately destroyed along the intestinal tract of the suckling infant.

\section{Conclusion}

Research in the field of complement system reactivity in human breast-milk is at a relatively early stage. Further efforts are likely to lead to the discovery of many interesting interactions between complement components and other natural components of human milk. The physiological significance of the complement in protecting the mammary gland and the nursing infant can no longer be denied. The presence of a wide range of inhibitors of complement probably serve to limit the activation of the complement system in the fluid-phase, avoiding the consequent risk of widespread damage to soft tissues by associated inflammatory processes, while promoting the solid-phase activation of the reaction cascade. The milk fat globule membrane thereby acts as a most suitable template to support the solid-phase reactivities.

Understanding the actual mechanisms of the complement reaction cascade and interaction with such a wide variety of inhibitors present in the aqueous phase of human milk, is the real challenge for investigators in the coming decades.

ACKNOWLEDGEMENTS. The author is extremely grateful to the German Academic Exchange Services (DAAD) which provided sponsorship for this study. The author is also greatly indebted to Professors Otto Götze and Reiner Thomssen, for their kind supervision and encouragement during the period of this study. The kind assistance of Dr Robert Giessler, who painstakingly reviewed the manuscript and provided helpful comments, as well as the support of other members of the Departments of Immunology and Microbiology, are hereby highly appreciated.

\section{References}

1. Loos M. The classical complement pathway: mechanism of activation of the first component by antigen-antibody complexes. Prog Allergy 1982 30: $135-192$.

2. Gotze O, Muller-Eberhard HJ. The alternative pathway of complement activation. Adv Immunol 1976: 24: 1-35

3. McClelland DB, McGrath J, Samson RR. Antimicrobial factors in human milk. Studies of concentration and transfer to the infant during the early stages of lactation. Acta Paediatr Scand Suppl 1978: 271: 1-20.

4. Lewis-Jones DI, Lewis-Jones MS, Connolly RC, Lloyd DC, West CR. Sequential changes in the antimicrobial protein concentrations in human milk during lactation and its relevance to banked human milk. Pediatr Res 1985: 19(6): 561-565.

5. Ballow M, Fang F, Good RA, Day NK. Developmental aspects of complement components in the newborn. The presence of complement components and C3 proactivator (properdin factor B) in human colostrum. Clin Exp Immunol 1974: 18(2): 257-266.

6. Minta JO, Jezyk PD, Lepow IH. Distribution and levels of properdin in human body fluids. Clin Immunol Immunopatbol 1976: 5(1): 84-90.

7. Cole FS, Schneeberger EE, Lichtenberg NA, Colten HR. Complement biosynthesis in human breast-milk macrophages and blood monocytes. Immunology 1982: 46(2): 429-441.

8. Rainard P, Poutrel B, Caffin JP. Assesssment of hemolytic and bactericidal complement activities in normal and mastitic bovine milk. J Dairy Sci 1984: 67(3): 614-619.

9. Reiter B, Brock JH. Inhibition of Escherichia coli by bovine colostrum and post-colostral milk. I. Complement-mediated bactericidal activity of antibodies to a serum susceptible strain of $E$. coli of the serotype O 111 . Immunology 1975; 28 (1): 71-82.

10. Ogundele MO. Anti-complement activities of human breast-milk. (In Review).

11. Aramini JM, Drakenberg T, Hiraoki T, Ke Y, Nitta K, Vogel HJ. Calcium-43 NMR studies of calcium-binding lysozymes and alpha-lactalbumins Biochemistry 1992: 31(29): 6761-6768.

12. Mayer MM. Complement Fixation. In: Kabat EA, Mayer MM, eds. Experimental Immunochemistry, 2nd edn. Springfield, IL: Charles C. Thomas, 1971: 133-159.

13. Veerhuis R., Kjiilstra A. Inhibition of hemolytic complement activity by lactoferrin in tears. Exp Eye Res 1982: 34: 257-265.

14. Kjiilstra A, Jeurissen SHM. Modulation of classical C3 convertase complement by tear lactoferrin. Immunology 1982: 47: 263-270.

15. Ogundele MO. A novel anti-inflammatory activity of lysozyme: modulation of serum complement activation. Mediators Inflammation 1998: 7(5): 363-365.

16. Iida K, Fujita T, Inai S, Sasaki M, Kato T, Kobayashi K. Complement fixing abilities of IgA myeloma proteins and their fragments: the activation of complement through the classical pathway. Immunochemistry 1976 13(9): 747-752.

17. Russell MW, Mansa B. Complement-fixing properties of human IgA antibodies. Alternative pathway complement activation by plastic-bound, but not specific antigen-bound, IgA. Scand J Immunol 1989: 30(2): $175-183$

18. Russell MW, Reinholdt J, Kilian M. Anti-inflammatory activity of human IgA antibodies and their Fab alpha fragments: inhibition of IgG-mediated complement activation. Eur J Immunol 1989: 19(12): 2243-2249. 
19. Nikolova EB, Tomana M, Russell MW. All forms of human IgA anti bodies bound to antigen interfere with complement (C3) fixation induced by IgG or by antigen alone. Scand J Immunol 1994: 39(3): 275-280.

20. Spiegelberg HL, Götze O. Conversion of C3 proactivator of the alternative pathway of complement by different classes and subclasses of human immunoglobulins (Abstracts). Fed Proc Fed Am Soc Exp Biol 1972: 31: 655 .

21. Hakulinen $J$, Meris S. Shedding and enrichment of the glycolipidanchored complement lysis inhibitor protectin (CD59) into milk fat globules. Immunology 1995: 85(3): 495-500.

22. Meri S, Väkevä A, Laari T, Lachmann PJ. Soluble forms of CD59-antigen: distribution in body fluids and functional activity. In: XIVth Int Complement Workshop (Abstract) 1996: 193.

23. Long KE, Yomtovian R, Kida M, Knez JJ, Medof ME. Time-dependent loss of surface complement regulatory activity during storage of donor blood. Transfusion 1993: 33: 294-300.

24. Medof ME, Walter EI, Rutgers JL, Knowles DM, Nussenzweig V. Identification of the complement decay-accelerating factor (DAF) on epithelium and glandular cells and in body fluids. J Exp Med 1987: 165(3): 848-864.

25. Sack RA, Underwood A, Tan KO, Morris C. Vitronectin in human tearsprotection against closed eye induced inflammatory damage. Adv Exp Med Biol 1994: 350: 345-349.

26. Moffatt BE, Sim RB. Complement factor $\mathrm{H}$ and related proteins in human body fluids. Immunology (Suppl) 1995: 86: 162 (Abstract).

27. Okamoto U, Horie N, Nagamatsu Y, Yamamoto JI. Plasminogen-activator in human early milk: its partial purification and characterization. Thromb Haemost 1981: 45(2): 121-126.

28. Greenberg R, Groves ML. Plasmin cleaves human beta-casein. Biochem Biophys Res Commun 1984: 125(2): 463-468.

29. Goldman AS, Goldblum RM, Hanson LA. Anti-inflammatory systems in human milk. Adv Exp Med Biol 1990: 262: 69-76.

30. Ajusi JD, Onyango FE, Mutanda LN, Wamola IA. Bacteriology of unheated expressed breast milk stored at room temperature. East Afr Med J 1989: 66(6): 381-387.

31. Bjöksten B, Burman LG, De Chateau P, Fredrikzon BO, Gothefors L, Hernell O. Collecting and banking human milk: to heat or not to heat. $\mathrm{Br}$ Med J 1980: 281: 765-769.

32. Franke WW, Heid HW, Grund C, Winter S, Freudenstein C, Schmid E, Jarasch ED, KeenanTW. Antibodies to the major insoluble milk fat globule membrane-associated protein: specific location in apical regions of lactating epithelial cells. J Cell Biol 1981: 89(3): 485-494.
33. Welsch U, Schumacher U, Buchheim W, Schinko I, Jenness P, Patton S Histochemical and biochemical observations on milk-fat-globule membranes from several mammalian species. Acta Histochem Suppl 1990: 40: 59-64

34. Lavine M, Clark RM. Changing patterns of free fatty acids in breast milk during storage. J Pediatr Gastroenterol Nutr 1987: 6(5): 769-774.

35. Ballow M, Donshik PC, Mendelson L. Complement proteins and C3 anaphylatoxin in the tears of patients with conjunctivitis. J Allergy Clin Immunol 1985: 76(3): 473-476.

36. Isaacs CE, Kashyap S, Heird WC, Thormar H. Antiviral and antibacterial lipids in human milk and infant formula feeds. Arch Dis Child 1990: 65(8): 861-864.

37. France GL, Marmer DJ, Steele RW. Breast-feeding and Salmonella infection. Am J Dis Child 1980: 134(2): 147-152.

38. Prentice A, Prentice AM, Lamb WH. Mastitis in rural Gambian mothers and the protection of the breast by milk antimicrobial factors. Trans $R$ Soc Trop Med Hyg 1985: 79(1): 90-95.

39. Morgan EL, Thoman ML, Hoeprich PD, Hugli TE. Bioactive complement fragments in immunoregulation. Immunol Lett 1985: 9(4): 207-213.

40. Schroten H, Hanisch FG, Plogmann R, Hacker J, Uhlenbruck G, Nobis Bosch R, Wahn V. Inhibition of adhesion of S-fimbriated Escherichia coli to buccal epithelial cells by human milk fat globule membrane components: a novel aspect of the protective function of mucins in the nonimmunoglobulin fraction. Infect Immun 1992: 60(7): 2893-2899.

41. Rainard P, Poutrel B. Deposition of complement components on Streptococcus agalactiae in bovine milk in the absence of inflammation. Infect Immun 1995: 63(9): 3422-3427.

42. Crago SS, Prince SJ, Pretlow TG, McGhee JR, Mestecky J. Human colostral cells. I. Separation and characterization. Clin Exp Immunol 1979: 38(3): 585-597.

43. Schroten H, Uhlenbruck G, Hanisch FG, van Mil A [Varying rates of phagocytosis of human blood monocytes and breast milk macrophages: effect of intralipid and milk fat globules] Unterschiedliche Phagozytoserate menschlicher Blutmonozyten und Muttermilchmakrophagen: Einfluss von Intralipid und Milchfettkügelchen. Monatsschr Kinderbeilk 1987: 135(1): 36-40.

44. Barriga C, Pombero I, Duran J, Forner A, Cardesa J, Rodriguez AB. Serum hemolytic and bactericidal activity in breast- and formula-fed infants. 1995; 51(4): 213-218.

\section{Received 12 January 1999; accepted 12 January 1999}




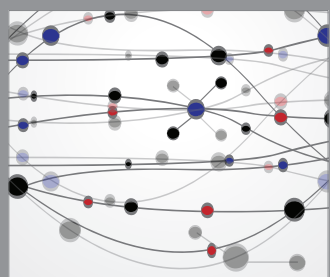

The Scientific World Journal
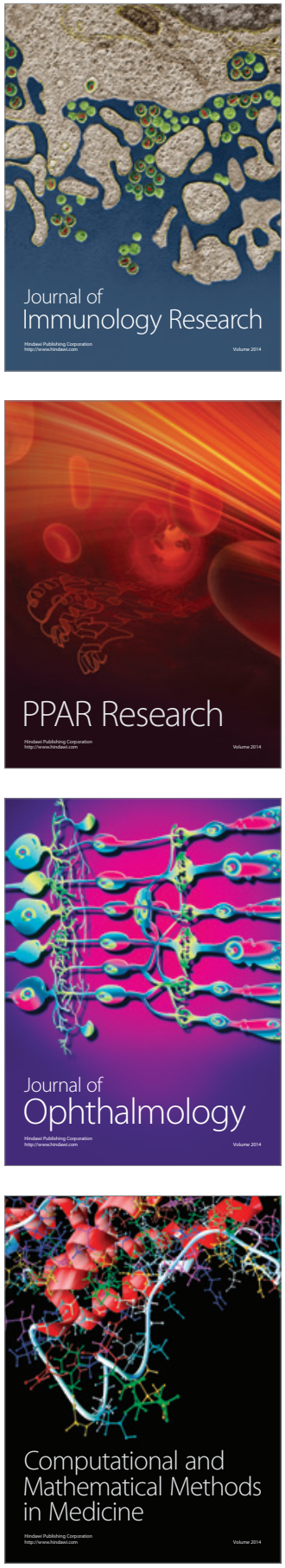

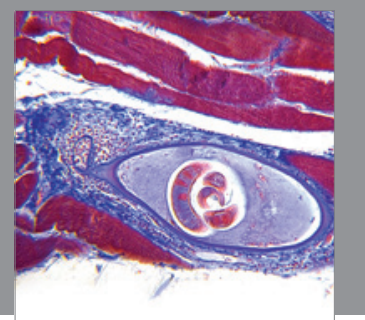

Gastroenterology

Research and Practice
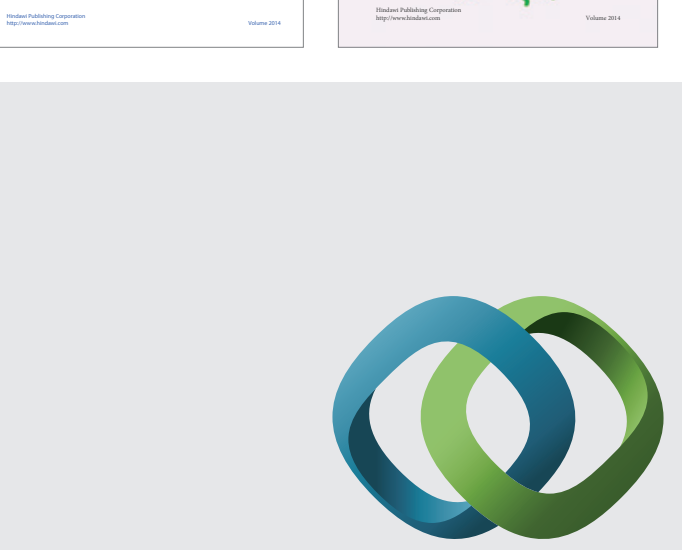

\section{Hindawi}

Submit your manuscripts at

http://www.hindawi.com
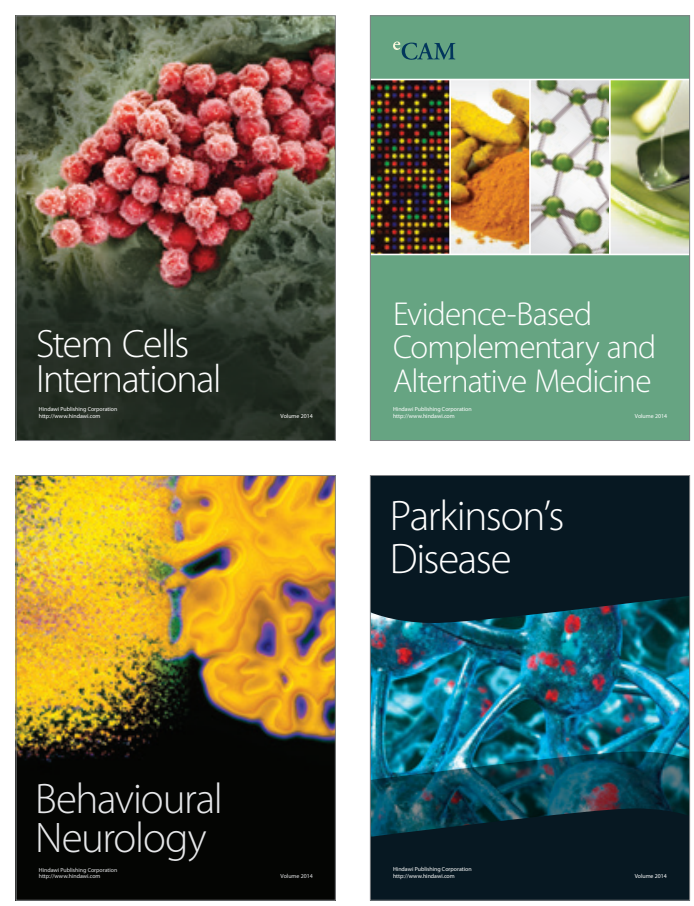

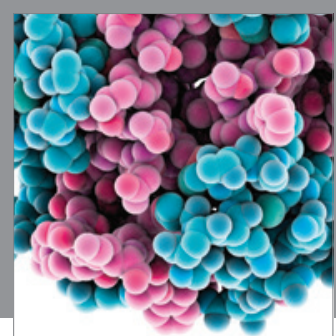

Journal of
Diabetes Research

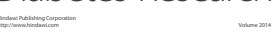

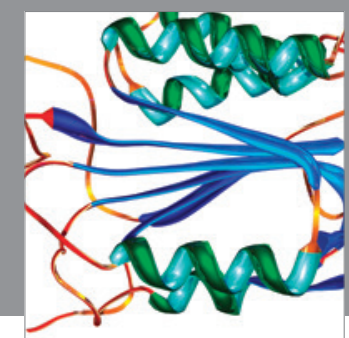

Disease Markers
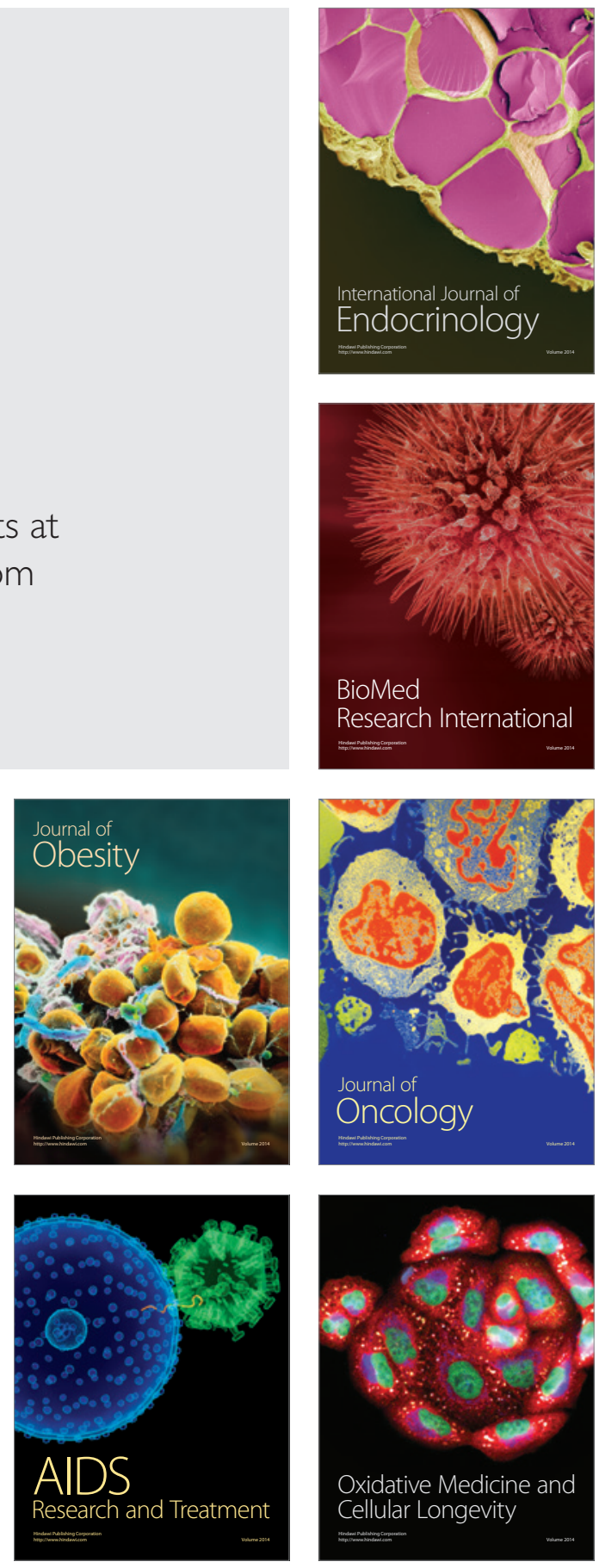